This document is confidential and is proprietary to the American Chemical Society and its authors. Do not copy or disclose without written permission. If you have received this item in error, notify the sender and delete all copies.

\title{
Biocompatible Polymer-Peptide Hybrid-Based DNA Nanoparticles for Gene Delivery
}

\begin{tabular}{|r|l|}
\hline Journal: & ACS Applied Materials \& Interfaces \\
\hline Manuscript ID: & am-2015-01684v.R2 \\
\hline Danuscript Type: & Article \\
\hline Date Submitted by the Author: & 23-Apr-2015 \\
\hline Complete List of Authors: & $\begin{array}{l}\text { Witzigmann, Dominik; University of Basel, } \\
\text { Wu, Dalin; Department of Chemistry, University of Basel, } \\
\text { Schenk, Susanne; University of Basel, } \\
\text { Balasubramanian, Vimalkumar; University of Helsinki, } \\
\text { Meier, Wolfgang; University of Basel, Department of Chemistry } \\
\text { Huwyler, Jörg; University of Basel, Institute of Pharmaceutical Technology }\end{array}$ \\
\hline
\end{tabular}

SCHOLARONE

Manuscripts 


\title{
Biocompatible Polymer-Peptide Hybrid-Based DNA Nanoparticles for Gene Delivery
}

\author{
Dominik Witzigmann ${ }^{a+}$, Dalin Wu ${ }^{b \dot{+}}$, Susanne H. Schenk ${ }^{a}$, Vimalkumar Balasubramanian ${ }^{a c}$, \\ Wolfgang Meier ${ }^{b}$, Jörg Huwyler ${ }^{a^{*}}$ \\ ${ }^{a}$ Division of Pharmaceutical Technology, Department of Pharmaceutical Sciences, University of \\ Basel, Basel, Switzerland \\ ${ }^{\mathrm{b}}$ Department of Chemistry, University of Basel, Switzerland \\ ${ }^{c}$ Division of Pharmaceutical Chemistry and Technology, Faculty of Pharmacy, University of \\ Helsinki, Helsinki, Finland \\ $\$$ Both authors contributed equally to this work. \\ * Author for correspondence
}




\begin{abstract}
Currently, research on polymers to be used as gene delivery systems is one of the most important directions in both polymer science and biomedicine. In this report, we describe a five-step procedure to synthesize a novel polymer-peptide hybrid system for gene transfection. The block copolymer based on the biocompatible polymer poly(2-methyl-2-oxazoline) (PMOXA) was combined with the biocleavable peptide block poly(aspartic acid) (PASP) and finally modified with diethylenetriamine (DET). PMOXA- $b$-PASP(DET) was produced in high yield and characterized by ${ }^{1} \mathrm{H}-\mathrm{NMR}$ and FT-IR. Our biopolymer complexed plasmid DNA (pDNA) efficiently, and highly uniform nanoparticles with a slightly negative zeta potential were produced. The polymer-peptide hybrid system was able to efficiently transfect HEK293 and HeLa cells with GFP pDNA in vitro. Unlike the commonly used polymer, 25kDa branched poly(ethylenimine), our biopolymer had no adverse effects on cell growth and viability. In summary, the present work provides valuable information for the design of new polymer-peptide hybrid-based gene delivery systems with biocompatible and biodegradable properties.
\end{abstract}

\title{
KEYWORDS \\ polymer-peptide hybrid system; transfection; gene delivery; nanoparticles; toxicity; biodegradability;
}




\section{INTRODUCTION}

Gene therapy is one of the most rapidly growing areas in nanomedicine research ${ }^{1}$. In general, gene delivery systems are classified into two major groups, i.e., viral and non-viral ${ }^{2}$. Viral vectors, such as retroviruses or adenoviruses, are characterized by high transfection efficacies, but their major drawback is the concern about biosafety and cytocompatibility ${ }^{3}$. Non-viral systems, such as lipids or polymers, have gained attention especially because of their lower cytotoxicity and easier production ${ }^{4}$. In particular, polymers have a great potential for gene therapy because of their chemical versatility ${ }^{5,6}$.

Many groups developed polymers or polymer conjugates with linear, branched, or cyclic molecule structure for gene delivery to express exogenous proteins ${ }^{3,7-14}$. To be translated into a protein, pDNA needs to overcome two barriers. Firstly, pDNA has to cross the cell membrane, and secondly, it must overcome the nuclear membrane. In the nucleus, pDNA will be transcribed into mRNA, and the protein of interest will be expressed.

Polycations are the major type of non-viral polymeric gene nanocarriers. The most widely used transfection polymer is $25 \mathrm{kDa}$ branched poly(ethylenimine) (bPEI) ${ }^{15}$. However, bPEI as well as several other polymers including poly(L-lysine) (PLL), poly(propylenimine) (PPI), and poly(2-dimethylamino ethyl methacrylate) (PDMAEMA) have cytotoxic side-effects ${ }^{16-18}$. Therefore, developments are focusing on gene vectors with improved transfection efficiency as well as decreased cytotoxicity. Several approaches have already been investigated, e.g. ternary complexes consisting of PLL, pDNA, and a functional polymer ${ }^{19,20}$, single cyclic knot polymer structures $^{21}$, or highly branched degradable copolymers ${ }^{22}$. 
The main objective of the present work was the development of a novel polymer-peptide hybrid (PPH) based gene delivery system with minimal cytotoxicity, improved biocompatibility, and advantageous physico-chemical characteristics. PPH systems have recently attracted great attention because this type of block copolymers combines the excellent safety and biocompatibility profiles of both synthetic polymers and natural peptides ${ }^{3,7,10,23}$. We synthesized a block copolymer by ring-opening polymerization of 2-methyl-2-oxazoline and $\beta$-benzyl-Laspartate N-carboxy anhydride (BLA-NCA), using the synthetic polymer poly(2-methyl-2-oxazoline) (PMOXA) and the peptide block poly(aspartic acid) (PASP).

PMOXA is a hydrophilic polymer with stealth ${ }^{24}$ and protein-repellent properties ${ }^{25}$, which is an advantage for biomedical application ${ }^{26}$. In vivo, the circulation half-life is prolonged, and immunogenicity of the gene delivery system is reduced ${ }^{27}$. Recently, Pidhatika et al. demonstrated that under physiological conditions, PMOXA is more stable than polyethylene glycol (PEG) ${ }^{28}$. This suggests that PMOXA might be an excellent alternative to PEG. Thus, we used PMOXA as biocompatible and protein-repellent backbone of the gene delivery system. To the best of our knowledge, our biopolymer is the first PMOXA-based PPH for gene delivery.

PASP is a biocompatible and biodegradable polypeptide that can be used for further functionalization of the co-polymer ${ }^{29,30}$. In order to deliver nucleic acids with our PPH, the peptide block was easily modified with the amine-containing unit, diethylenetriamine (DET). Flanking primary and secondary amines allow for electrostatic interactions with the negatively charged backbone of nucleic acids ${ }^{31}$. This is necessary to complex pDNA and to form nanoparticles. Transfection efficiency of our tailor-made PPH PMOXA- $b$-PASP(DET) in mammalian cells was assessed using pDNA encoding green fluorescence protein (GFP). In 
addition, we evaluated the biocompatibility of our PPH in vitro as well as in vivo in a preliminary safety study. 


\section{EXPERIMENTAL SECTION}

\section{Materials}

Agarose and sodium dodecyl sulfate (SDS) were purchased from Bio-Rad Laboratories (Cressier, Switzerland), and 3-(4,5-dimethylthiazole-2-yl)-2,5-diphenyltetrazolinium bromide (MTT) and 1\% ethidium bromide solution were obtained from Carl Roth (Karlsruhe, Germany). Opti-MEM and $0.25 \%$ trypsin-EDTA were obtained from Invitrogen, Life Technologies (Zug, Switzerland). Cell media and all other chemicals were purchased from Sigma (Buchs, Switzerland): N-(2-hydroxyethyl)phthalimide (99\%), trifluoromethanesulfonic anhydride $(\geq 99 \%), \quad$ triethylamine $(\geq 99 \%), \quad$-methyl-2-oxazoline $(98 \%)$, sodium azide $(\geq 99.5 \%)$, hydrazine monohydrate (98\%), $\beta$-benzyl-L-aspartate (98\%), triphosgene (98\%), DET (99\%), calcium hydride $(95 \%)$, acetonitrile $(\geq 99.8 \%)$, dichloromethane $(\geq 99.8 \%)$, ethanol $(99.8 \%)$, N,N-dimethylformamide $\quad(\geq 99.8 \%), \quad$ and tetrahydrofuran $\quad(\geq 99.9 \%) . \quad$ Triethylamine, dichloromethane, 2-methyl-2-oxazoline, and acetonitrile were separated from $\mathrm{CaH}_{2}$, and tetrahydrofuran was separated from $\mathrm{LiAlH}_{4}$ by distillation. Other chemicals and solvents were used without additional purification.

\section{Synthesis and Characterization of PMOXA- $b$-PASP(DET)}

The PPH PMOXA- $b$-PASP(DET) was synthesized via a five-step procedure (Fig. 1A). A ${ }^{1} \mathrm{H}-\mathrm{NMR}$ was recorded on a Bruker DPX-400 MHz spectrometer in $\mathrm{CDCl}_{3}$ and $\mathrm{D}_{2} \mathrm{O}$ and was analyzed using MestReNova software. The molecular weight of our PPH was assessed using ${ }^{1}$ H-NMR. Due to poor solubility of our PPH in THF, a reliable determination of the molecular weight using gel permeation chromatography (GPC) was not possible. Fourier transform infrared spectroscopy (FT-IR) (PerkinElmer Spectrum 100 FT-IR Spectrometer) was used to characterize 
the presence of specific chemical groups. Polymer samples were measured with 256 scans and $2 \mathrm{~cm}^{-1}$ resolution. The spectra were measured from $400 \mathrm{~cm}^{-1}$ to $3000 \mathrm{~cm}^{-1}$.

\section{Phthalimidoethyl Triflate}

N-(2-hydroxyethyl)phthalimide $(0.63 \mathrm{~g}, 3.30 \mathrm{mmol})$ and trimethylamine (TEA, $0.60 \mathrm{~mL}$, $4.30 \mathrm{mmol}$ ) were first dissolved in $20 \mathrm{~mL}$ distilled dichloromethane (DCM) at $-20^{\circ} \mathrm{C}$. Afterwards, trifluoromethanesulfonic anhydride $(0.67 \mathrm{~mL}, 4.0 \mathrm{mmol})$ was mixed with another $5 \mathrm{~mL}$ distilled DCM and then dropped slowly into the solution under argon. The final solution was stirred for $3 \mathrm{~h}$ at $-20^{\circ} \mathrm{C}$ under argon atmosphere. After washing with cold saturated $\mathrm{NaHCO}_{3}$ aqueous solution and brine, the organic phase was dried by water-free $\mathrm{MgSO}_{4}$. After filtration of $\mathrm{MgSO}_{4}$, the solvent was evaporated, and the residues were dried in high vacuum for $2 \mathrm{~h}$ before further use.

\section{$N_{3}-P M O X A-P h$}

The initiator, phthalimidoethyl triflate $(0.97 \mathrm{~g}, 3.0 \mathrm{mmol})$, was dissolved in $30 \mathrm{~mL}$ distilled acetonitrile, and then distilled 2-methyl-2-oxazoline $(22 \mathrm{~mL}, 259 \mathrm{mmol})$ was added. Finally, the polymerization medium was heated to $80^{\circ} \mathrm{C}$ for $24 \mathrm{~h}$ under argon. The medium was cooled down to room temperature (RT), and a 10-fold excess of $\mathrm{NaN}_{3}$ was added to the medium to quench the polymerization and introduce the azide functional group. The medium was stirred for $24 \mathrm{~h}$ at RT. $\mathrm{NaN}_{3}$ was removed by filtration, and the solvent was evaporated. The final product was purified by dialysis against water for $48 \mathrm{~h}$. $\mathrm{N}_{3}$-PMOXA-Ph $(20 \mathrm{~g})$ was obtained by freeze-drying as a colorless powder. The yield was 91\%. ${ }^{1} \mathrm{H}-\mathrm{NMR}\left(400 \mathrm{MHz}, \delta, \mathrm{CDCl}_{3}\right): 2.0 \mathrm{ppm}\left(\mathrm{m}, \mathrm{O}=\mathrm{C}-\mathrm{CH} H_{3}\right.$, $\left.\mathrm{H}_{\mathrm{b}}\right), 3.44-3.54 \mathrm{ppm}\left(\mathrm{m},-\mathrm{CH}_{2}-\mathrm{CH}_{2^{-}}, \mathrm{H}_{\mathrm{c}}\right)$, 7.35-7.60 ppm (m, $\left.-\mathrm{C}_{6} \mathrm{H}_{4}, \mathrm{H}_{\mathrm{a}}\right)$. 
$\mathrm{N}_{3}-\mathrm{PMOXA}-\mathrm{NH}_{2}$

$\mathrm{N}_{3}$-PMOXA-Ph (4.25 g, $\left.0.55 \mathrm{mmol}\right)$ was dissolved in ethanol (100 mL). Hydrazine monohydrate $(400 \mathrm{~mL})$ was added, and the solution was stirred overnight under argon at RT. After evaporation of the solvent, the polymer was re-dissolved in $\mathrm{MeOH}$ and precipitated twice in cold diethyl ether. The polymer was then re-dissolved in water and dialyzed against water for 48 h. $\mathrm{N}_{3}-\mathrm{PMOXA}-\mathrm{NH}_{2}$ (3.8 g) was obtained by freeze-drying as a colorless powder, the yield was $89 \%$. ${ }^{1} \mathrm{H}-\mathrm{NMR}\left(400 \mathrm{MHz}, \delta, \mathrm{CDCl}_{3}\right)$ : $1.91 \mathrm{ppm}\left(\mathrm{m}, \mathrm{O}=\mathrm{C}-\mathrm{CH}_{3}, \mathrm{H}_{\mathrm{b}}\right), 3.38-3.50 \mathrm{ppm}$ $\left(\mathrm{m},-\mathrm{CH}_{2}-\mathrm{CH}_{2}-, \mathrm{H}_{\mathrm{c}}\right)$.

$\mathrm{N}_{3}-\mathrm{PMOXA}-\mathrm{PBLA}-\mathrm{NH}_{2}$

$\mathrm{N}_{3}$-PMOXA-NH $2(0.90 \mathrm{~g}, 0.12 \mathrm{mmol})$ was dissolved in water-free DMF. $\beta$-Benzyl L-aspartate anhydride $(2.9 \mathrm{~g}, 11.62 \mathrm{mmol})$ was added, and the reaction medium was continually stirred for $24 \mathrm{~h}$ at RT under argon atmosphere. The reaction medium was precipitated twice in cold diethyl ether to get $3 \mathrm{~g}$ of a colorless solid. The yield was $79 \% .{ }^{1} \mathrm{H}-\mathrm{NMR}\left(400 \mathrm{MHz}, \delta, \mathrm{CDCl}_{3}\right): 2.10$ ppm (m, O=C-CH3, $\mathrm{Hb}), 2.66$ ppm (broad, $\left.-\mathrm{CH}_{2}-\mathrm{C}=\mathrm{O}, \mathrm{Hd}\right), 3.11 \mathrm{ppm}\left(\mathrm{br},-\mathrm{CH}_{2}-\mathrm{C}=\mathrm{O}, \mathrm{Hd}\right), 3.45$ ppm (m, - $\left.\mathrm{CH}_{2}-\mathrm{CH}_{2-}, \mathrm{Ha}\right), 4.28$ ppm (br, $\left.\mathrm{CH}-\mathrm{NH}-, \mathrm{Hc}\right), 5.09$ ppm (m, $-\mathrm{CH}_{2}-\mathrm{C}_{6} \mathrm{H}_{5}, \mathrm{He}$ ), 7.25 ppm (m, $\left.\mathrm{C}_{6} H_{5^{-}}, \mathrm{Hf}\right), 8.87$ ppm (br, $\mathrm{O}=\mathrm{C}-\mathrm{NH}-, \mathrm{Hg}$ ).

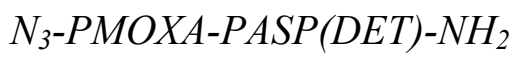

$\mathrm{N}_{3}$-PMOXA-PBLA-NH $2(0.052 \mathrm{~g}, 0.0029 \mathrm{mmol})$ was dissolved in water-free DMF $(4 \mathrm{~mL})$, then DET $(0.75 \mathrm{~mL}, 6.9 \mathrm{mmol})$ was added. The reaction was carried out at $40^{\circ} \mathrm{C}$ under argon for $36 \mathrm{~h}$. The reaction medium was added to $20 \mathrm{~mL}$ acetic acid aqueous solution $(10 \%)$ and then dialyzed against a $0.01 \mathrm{~N} \mathrm{HCl}$ aqueous solution for $48 \mathrm{~h}$. A slightly yellow colored solid powder (50 mg) was obtained after lyophilisation. The yield was $98 \%$. ${ }^{1} \mathrm{H}-\mathrm{NMR}\left(400 \mathrm{MHz}, \delta, \mathrm{D}_{2} \mathrm{O}\right)$ : 1.99 ppm (m, O=C-CH3, $\mathrm{Hb}), 2.83$ ppm (m, O=C-NH-CH, $\mathrm{He}), 2.90$ ppm (br, $\left.-\mathrm{CH}_{2}-\mathrm{C}=\mathrm{O}, \mathrm{Hd}\right)$, 
$3.02 \mathrm{ppm}\left(\mathrm{m},-\mathrm{CH}_{2}-\mathrm{NH}-\mathrm{CH}_{2}-\right.$, Hf), 3.13 ppm (br, O=C-CH-NH-, Hc), 3.36 ppm (br, $-\mathrm{CH}_{2}-\mathrm{NH}_{2}$, $\mathrm{Hg}), 3.43-3.53 \mathrm{ppm}\left(\mathrm{m},-\mathrm{CH}_{2}-\mathrm{CH}_{2}-\mathrm{N}, \mathrm{Ha}\right)$.

\section{Cell Culture}

Human embryonic kidney (HEK293) cells and the human epithelial carcinoma cell line HeLa were cultured at $37^{\circ} \mathrm{C}$ under $5 \% \mathrm{CO}_{2}$ and saturated humidity in Dulbecco's modified Eagle's culture medium high glucose (DMEM) supplemented with 10\% fetal calf serum (FCS), penicillin (100 units/mL), and streptomycin $(100 \mu \mathrm{g} / \mathrm{mL})$. HEK293 cells stably expressing GFP for growth characteristic studies were produced by single-cell sorting and were cultured in DMEM containing 10\% FCS and $0.5 \mathrm{mg} / \mathrm{mL}$ Geneticin ${ }^{\circledR}$ (G418, Invitrogen, Life Technologies). Transfection assays were performed using the mammalian expression plasmid pTagGFP-N (Evrogen) with a size of $4.7 \mathrm{~kb}$. The pDNA vector is encoding the enhanced GFP and comprises the immediate early promotor of cytomegalovirus (CMV).

\section{pDNA Complexation}

To form polymer-pDNA complexes, PMOXA- $b$-PASP(DET) or bPEI were mixed with pDNA in $100 \mu \mathrm{L}$ complexation medium in defined nitrogen to phosphate $(\mathrm{N} / \mathrm{P})$ ratios and incubated for 30 min at RT. As complexation medium we tested Opti-MEM (pH 7.4), acetate buffer ( $\mathrm{pH}$ 5.5), and tris-buffered saline (TBS; $\mathrm{pH}$ 8.0). The resulting polymer-pDNA complexes were used for further experiments. For the N/P ratio calculations, we assumed a mass of $179 \mathrm{~g} / \mathrm{mol}$ for each amine-containing unit of our PPH, $43.1 \mathrm{~g} / \mathrm{mol}$ for each amine-containing unit of bPEI, and $330 \mathrm{~g} / \mathrm{mol}$ for each phosphate-containing unit of the pDNA. 


\section{Gel Retardation Assay}

Freshly prepared PMOXA- $b$-PASP(DET)-pDNA complexes with N/P ratios of 0.5 to 300 were analyzed by gel retardation assay. Samples containing either pDNA only or PMOXA- $b$-PASP(DET) only (mock control) were used as controls. For tracking, a loading buffer (15\% Ficoll 400 in tris/borate/EDTA buffer [TBE]) containing bromophenol blue (0.1\%) was added to each sample. All samples were separated on a $0.8 \%$ agarose gel containing $0.05 \mathrm{mg} / \mathrm{mL}$ ethidium bromide (EtBr) at $80 \mathrm{~V}$ for $45 \mathrm{~min}$ using TBE buffer. A gel documentation system (GelDoc-It TS2 Imager, UVP, Cambridge, UK) was used to visualize pDNA migration.

\section{PPH-pDNA-Nanocomplex Characterization}

\section{Morphology}

Particle size and morphology of nanocomplexes were analyzed using transmission electron microscopy (TEM). Samples were loaded on a carbon-coated grid and stained negatively with $2 \%$ uranylacetate solution. Excess of uranylacetate was removed, and the samples were dried at RT overnight. TEM analysis was performed with a CM-100 electron microscope (Philips, Eindhoven, Netherlands).

Size

Tunable resistive pulse sensing (TRPS) analysis was performed using the qNano (Izon Science, Christchurch, New Zealand). Particle size, size distribution, and concentration of PPH-pDNA-nanoparticles at N/P ratios of 100 and 300 were analyzed. The nanoparticles were passed through a tunable nanopore with size designation np300. Calibration was performed with $115.0 \mathrm{~nm}$ carboxylated polystyrene nanoparticles. Degree of membrane stretch $(46.05 \mathrm{~mm})$ and applied voltage $(0.70 \mathrm{~V})$ were tuned to optimize the resolution for each preparation. 


\section{Zeta Potential}

Zeta potential of the polymer-pDNA nanocomplexes (PPH or bPEI) was measured using a Delsa Nano C Particle Analyzer (Beckman Coulter, Nyon, Switzerland). Laser wavelength was $658 \mathrm{~nm}$, and measurement angle was $15^{\circ}$. Samples were measured in D-PBS at RT by electrophoretic light scattering. Data were converted using the Smoluchowski equation (Delsa Nano V3.73/2.30, Beckman Coulter Inc., Brea, USA).

\section{Stability}

Stability of PMOXA- $b$-PASP(DET)-pDNA nanocomplexes was assessed using TEM analysis. Freshly prepared nanocomplexes were compared to nanocomplexes stored for two weeks in complexation medium at $4^{\circ} \mathrm{C}$. Sample preparation was performed as described before.

\section{GFP pDNA Transfection}

To assess the functionality of our PPH-based system, transfection assays were performed. In a 24-well plate, 120,000 HEK293 or HeLa cells were seeded and cultured in $1 \mathrm{~mL}$ DMEM. Cells were allowed to adhere for $24 \mathrm{~h}$. Then, $100 \mu \mathrm{L}$ of freshly prepared PMOXA- $b$-PASP(DET)pDNA complexes (N/P ratios 0 - 300) was added to each well. Controls ( $0 \%$ transfection) were defined as incubation of cells with DMEM and complexation buffer (Opti-MEM) only. Additionally, cells were incubated with pDNA alone to assess transfection efficiency without any transfection reagent. Autofluorescence of cells was determined by incubation of cells with the PPH only. GFP expression was analyzed qualitatively by confocal laser scanning microscopy (CLSM) or quantitatively by flow cytometry $48 \mathrm{~h}$ after transfection (see below). 


\section{GFP Expression Analysis}

\section{Confocal Laser Scanning Microscopy}

For qualitative analysis of GFP expression, cells were washed with D-PBS and cultured in DMEM without phenol red. Live cell imaging was performed using an Olympus FV-1000 inverted confocal fluorescence microscope (Olympus Ltd., Tokyo, Japan) and a 10x objective (numerical aperture 0.40). Excitation and emission wavelengths were $488 \mathrm{~nm}$ and $516 \mathrm{~nm}$, respectively. Surface area of GFP-positive cells was assessed using ImageJ 1.46 software (National Institutes of Health, USA).

Flow Cytometry

For quantitative analysis of GFP expression, cells were washed with cold D-PBS $\left(4^{\circ} \mathrm{C}\right)$ and detached using $0.25 \%$ trypsin/EDTA. After two additional washing steps with D-PBS, cells were resuspended in staining buffer containing D-PBS, 1\% FCS, 0.05\% $\mathrm{NaN}_{3}$, and $2.5 \mathrm{mM}$ EDTA. Flow cytometry analysis of 10,000 cells was carried out using a FACS Canto II flow cytometer (Becton Dickinson, San Jose, USA). The cells were excited at $488 \mathrm{~nm}$, and doublets were excluded. The fluorescence signal of GFP was detected in FL1 (505LP - 530/30). To evaluate the transfection efficacies (\% of GFP-positive cells), Flow Jo VX software (TreeStar, Ashland, OR) was used.

\section{Cell Viability Assay}

To evaluate the cytotoxic effect of PMOXA- $b$-PASP(DET) and bPEI, native or in complex with pDNA, an MTT assay was performed as described previously ${ }^{32}$. In brief, HEK293 or HeLa cells were incubated for $24 \mathrm{~h}$ with different concentrations of the test compounds. Afterwards, the cells were incubated with MTT reagent at $37^{\circ} \mathrm{C}$ and $5 \% \mathrm{CO}_{2}$ for $4 \mathrm{~h}$. In order to solubilize the 
reduced MTT for the readout, the culture medium was discarded and a solution containing $20 \mu \mathrm{L}$ $3 \%(\mathrm{v} / \mathrm{v})$ sodium dodecyl sulfate in water and $100 \mu \mathrm{L} 40 \mathrm{mM}$ hydrochloric acid in isopropanol was added. The water insoluble formazan dye crystals were dissolved in the dark for 2 hours at RT by shaking. Finally, the optical density at $570 \mathrm{~nm}$ was measured using a Spectramax M2 micro-plate reader (Molecular Devices, Sunnyvale, CA, US). The results are given as relative cell viability (RCV) compared to control cells (complexation medium only). Interference controls were performed to exclude the influence of PMOXA-b-PASP(DET) on the outcome of the assay.

\section{Analysis of Morphology and Cell Growth}

To assess the influence of PMOXA- $b$-PASP(DET) or bPEI on cell growth characteristics, HEK293 stably expressing GFP were seeded at a density of 10,000 cells/well in a 96-well plate. GFP-expressing HEK293 cells were used to improve the visibility of growth difference compared to non-treated control cells. Opti-MEM, PMOXA- $b$-PASP(DET), or bPEI was added $24 \mathrm{~h}$ after seeding. After an additional $48 \mathrm{~h}$, CLSM analysis was performed to assess morphological changes and cell growth. GFP-expressing HEK293 cells were analyzed by CLSM as described above. For quantitative analysis of growth area of cells, ImageJ 1.46 software was used.

\section{Statistical Analysis}

Statistical analysis of transfection experiments, MTT assays, and safety studies was performed by one-way analysis of variance (ANOVA) followed by a Bonferroni post-hoc test using OriginPro 9.1 (OriginLab Corporation; Northampton, USA) software. All data represent means $\pm \mathrm{SD}$ of at least $\mathrm{n}=3$ independent sets of experiments. 
Transfection efficiency of our PPH was optimized using a $2^{3}$ full factorial design of experiment (DoE) [Stavex 5.2 software, Aicos Technologies, Basel, Switzerland]. The studied variables included: (a) Opti-MEM (pH 7.4) or TBS (pH 8.0) as complexation medium, (b) N/P ratio 20 or 100, and (c) type of transfection protocol (i.e. direct application of transfection mix onto cells versus dilution of transfection mix in DMEM prior to addition). 


\section{RESULTS AND DISCUSSION}

\section{Synthesis and Characterization of PMOXA-b-PASP(DET)}

The main goal of the present work was to synthesize a novel, biocompatible PPH system for gene delivery. Phthalimidoethyl triflate was used as an educt for the chemical synthesis (Fig. 1A) ${ }^{33}$. Ring-opening polymerization of 2-methyl-2-oxazoline was quenched using $\mathrm{NaN}_{3}$. According to the ${ }^{1} \mathrm{H}-\mathrm{NMR}$ calculation, the degree of polymerization index was 90 (Table 1).

Finally, the azide functional group was connected to PMOXA (Fig. 1A). The appearance of chemical shift signals from $7.35 \mathrm{ppm}$ to $7.55 \mathrm{ppm}$ on ${ }^{1} \mathrm{H}-\mathrm{NMR}$ of $\mathrm{N}_{3}$-PMOXA-Ph proved the existence of phthalimide (Fig. 1B), indicating that there was no side reaction occurring between this protection group and 2-methyl-2-oxazoline during polymerization. In addition, absorbance at $2010 \mathrm{~nm}$ in the FT-IR proved the successful connection of the azide group on the polymer (Fig. 1C) ${ }^{34}$. The azide function offers the possibility to connect special targeting ligands through a click chemistry reaction.

The phthalimide group can be de-protected in the presence of hydrazine monohydrate to afford the primary amine ${ }^{35}$. The chemical shift at the position of $1.91 \mathrm{ppm}$ and $3.38 \mathrm{ppm}$ in the ${ }^{1} \mathrm{H}-$ NMR spectra of $\mathrm{N}_{3}$-PMOXA- $\mathrm{NH}_{2}$ demonstrated that the PMOXA backbone was kept intact in the presence of hydrazine monohydrate during the reaction (Fig. 1D).

$\mathrm{N}_{3}-\mathrm{PMOXA}-\mathrm{NH}_{2}$ was used as the macroinitiator to initiate ring-opening polymerization of $\beta$-benzyl L-aspartate anhydride in DMF solution. The new peaks with chemical shifts of $2.66 \mathrm{ppm}, 3.11 \mathrm{ppm}, 4.28 \mathrm{ppm}, 5.09 \mathrm{ppm}$, and $7.25 \mathrm{ppm}$ in the ${ }^{1} \mathrm{H}-\mathrm{NMR}$ demonstrated the successful synthesis of $\mathrm{N}_{3}$-PMOXA- $b$-PBLA with around 50 repeating units (Fig. 1E). To avoid intermolecular aminolysis reaction, $\mathrm{N}_{3}$-PMOXA- $b$-PBLA was treated with a 2500 -fold excess of 
DET. Disappearance of the benzyl group peaks and appearance of DET on chemical shift $2.83 \mathrm{ppm}, 3.02 \mathrm{ppm}$, and $3.36 \mathrm{ppm}$ in the ${ }^{1} \mathrm{H}-\mathrm{NMR}$ spectrum proved the successful modification of $\mathrm{N}_{3}$-PMOXA- $b$-PBLA with high density of DET (Fig. $1 \mathrm{~F}+$ Table 1 ). This functionality is needed to form a complex with negatively charged pDNA. In conclusion, PMOXA- $b$ PASP(DET) was successfully synthesized in high yield using a versatile five-step procedure. The different steps could be easily modified to change the physico-chemical characteristics of the biopolymer.

\section{Physico-chemical Characterization of PMOXA-b-PASP(DET) as Gene Delivery System}

Gene delivery systems have to meet a number of criteria for successful expression of proteins. These include: (I) efficient nucleic acid packaging, (II) entry into cell by endocytosis, (III) endosomal escape, (IV) intracellular DNA/carrier release, and (V) entry into the cell nucleus ${ }^{17,36,37}$. The first step for efficient transfection is complete complexation of pDNA by electrostatic interactions. PMOXA- $b$-PASP(DET) has several protonable amino groups with $\mathrm{pKa}$ values of 9.1 (secondary amine) and 6.3 (primary amine), resulting in a cationic charge at physiological $\mathrm{pH}(7.4)^{38}$. In order to assess the complexation power of the $\mathrm{PPH}$, we performed a gel retardation assay analysis (Fig. $2+$ Fig. S1). The positive charge of PMOXA- $b$-PASP(DET) compensates the negative charge of the pDNA, resulting in a polymer-pDNA nanocomplex with decreased charge. In addition, the PPH forms nanocomplexes with pDNA which are too big to migrate in the agarose gel.

Migration of nanocomplexes in the agarose gel slowed with increasing pDNA complexation (Fig. $2+$ Fig. S1 A-C). At N/P ratios of 4, we observed complete complexation and thus slowed migration of the pDNA in the agarose gel. Notably, this observation was independent of the $\mathrm{pH}$ 
(Fig. S1 A-C). Thus, we conclude that transfection experiments should be performed using an $\mathrm{N} / \mathrm{P}$ ratio of at least 4. PMOXA- $b$-PASP(DET) stored for a long period (nine months) in Opti-MEM (2 mg/mL) showed no ability anymore to complex pDNA (Fig. S1D). Thus, PPH solutions were always prepared freshly.

bPEI generally condenses pDNA completely already at N/P ratios of $1.5-2.0^{18}$. This difference can be explained by the fact that nitrogens in the PMOXA backbone of our PPH are part of amide bonds. Therefore, they cannot interact with pDNA by electrostatic interactions. The relative number of charged amino groups is lower compared to bPEI which consists only of a polycationic polymer.

TEM analysis of PPH-pDNA complexes formed at different N/P ratios between 0.5 and 300 was performed (Fig. 3). At an N/P ratio of 20, PPH-pDNA complexes started to form filamentous and ring-like morphologies (Fig. 3A). However, starting at an N/P ratio of 50, the PPH formed spherical structures with a diameter below $200 \mathrm{~nm}$ (Fig. 3B-D + Fig. S2). Interestingly, increasing N/P ratios decreased the size of the resulting PPH-pDNA nanoparticles. After two weeks in complexation medium, the PPH-pDNA complexes kept their initial, spherical morphology (Fig. S2). It should be noted that TEM analysis is a qualitative method, which cannot provide precise information on size distribution. This can be attributed to the fact that only a limited number of nanoparticles can be analyzed by TEM. Therefore, we used TRPS as a quantitative, precise, and very sensitive method. Mean particle diameter of the nanoparticles determined by TRPS was $109.8 \mathrm{~nm}$ at an N/P ratio of 100 and $101.2 \mathrm{~nm}$ at an N/P ratio of 300, confirming the corresponding TEM analysis (Fig. 3E+F). The d90/d10 values of 1.5 (N/P 100) and $1.4(\mathrm{~N} / \mathrm{P} 300)$ were indicative of a narrow and monodisperse size distribution of both 
nanoparticle types. Nanoparticles in this size range are considered to be optimal for DNA transfection and drug delivery since they can easily undergo endocytosis ${ }^{39,40}$.

The zeta potential of the PPH-pDNA nanoparticles increased with increasing N/P ratios, ranging from $-28.0 \pm 1.6 \mathrm{mV}(\mathrm{N} / \mathrm{P} 50)$ to $-11.4 \pm 2.0 \mathrm{mV}(\mathrm{N} / \mathrm{P} 100)$, and $-5.4 \pm 3.4 \mathrm{mV}$ (N/P 300). With increasing amounts of PMOXA- $b$-PASP(DET), the negative charge of pDNA was compensated to a larger degree. The PMOXA block in our PPH might stabilize the nanoparticles by steric repulsion overcoming lowered electrostatic repulsion. In contrast, bPEI-pDNA complexes at N/P ratios of 50,100 , and 300 showed positive zeta potentials $(14.4 \pm 2.0 \mathrm{mV}, 15.7 \pm 3.1 \mathrm{mV}$, and $14.8 \pm 2.6 \mathrm{mV}$, respectively).

The slightly negative zeta potential of our PPH-pDNA nanoparticles is favorable for biomedical applications in vitro as well as in vivo. Our results demonstrate that the slightly negative charge of our PPH-pDNA nanoparticles does not interfere with in vitro cell transfection. We therefore did not use higher $\mathrm{N} / \mathrm{P}$ ratios since negatively charged nanoparticles are known to be less cytotoxic and less prone to activate the immune system ${ }^{41}$. In addition, it is tempting to speculate that in vivo our slightly negative nanoparticles will be characterized by low volume of distribution and a long half-life in the circulation. In contrast, in vivo use of cationic nanoparticles is not possible due to their unspecific interaction with plasma membranes and their resulting rapid sequestration in the lung after intravenous administration ${ }^{42}$.

\section{Use of PMOXA-b-PASP(DET) as Gene Delivery System}

Our nanoparticle characterization data suggest that the PPH should be used at N/P ratios above 20. Therefore, we performed a $2^{3}$ full factorial DoE to evaluate the effect of $\mathrm{N} / \mathrm{P}$ ratio, complexation medium, and transfection method on transfection efficiency. Our model provided a 
good fit $\left(\mathrm{R}^{2}=0.9822\right)$. The complexation medium and N/P ratio were considered as important. The N/P ratio had a significant impact on transfection efficiency $(P=0.0002)$ followed by the complexation medium $(\mathrm{P}=0.0145)$. Interestingly, the transfection method had no statistically significant impact on transfection efficiency.

In the gel retardation assay we did not observe any difference in pDNA complexation of our PPH at different $\mathrm{pH}$ values (Fig. S1). Since it was recently reported that tris buffer enhances the transfection efficiency of polyplex solutions we used TBS for our $2^{3}$ full factorial DoE ${ }^{43}$. However, we observed that transfection using TBS ( $\mathrm{pH} 8.0$ ) was less efficient compared to Opti-MEM with a $\mathrm{pH}$ of 7.4. At lower $\mathrm{pH}$, more amine groups of the $\mathrm{PPH}$ are protonated allowing better complex formation of pDNA and PPH. It is important to note, that a physiological $\mathrm{pH}$ is favorable in respect to biocompatibility and evaluation of the nanoparticles in cell culture or in vivo. In conclusion, the best combination from our DoE model was the use of a physiological complexation medium and an N/P ratio of 100 .

For qualitative analysis of GFP expression in HEK293 and HeLa cells we used CLSM (Fig. 4A+C). Respective polymer-pDNA complexes were always prepared freshly for each experiment to minimize the effect of nucleases. Especially, because we observed a decreased amount of nanoparticles after storage for two weeks in complexation medium. As expected, cells treated with pDNA alone or cells treated with PMOXA- $b$-PASP(DET) alone (mock control) did not express GFP, while cells transfected with PMOXA- $b$-PASP(DET)-pDNA complexes showed GFP expression (Fig. 4A+C). The number of GFP-positive cells increased with increasing N/P ratios $(20$ - 300). In contrast, HEK293 and HeLa cells transfected with bPEI/pDNA showed the highest number of GFP-positive cells at an N/P ratio of 20 (Fig. 4A+C). When the N/P ratios 
were increased even more, the total number of cells decreased being indicative of cytotoxic effects of bPEI (Fig. 4A+C).

To underline our observation, we performed an image analysis of surface area of GFP-positive cells $(\%)$ as an indicator for the total number of transfected cells. In fact, the image analysis revealed that the surface area of GFP-positive cells decreased for higher bPEI N/P ratios. Increasing the $\mathrm{N} / \mathrm{P}$ ratio from 20 to 50 decreased the surface area of GFP-positive cells approximately $40 \%$. There was no indication of PPH-pDNA complex-induced cell toxicity despite the use of higher amounts of transfection reagent. The surface area of GFP-positive cells increased significantly from N/P ratio 20 to 300 in both human cell lines.

For an exact quantification of transfection efficiency, we performed a flow cytometry analysis using N/P ratios not showing any cellular toxicity in CLSM studies. Neither PPH alone nor pDNA alone resulted in transfection of cells (Fig. 4B+D). bPEI $(\mathrm{N} / \mathrm{P}=20)$ yielded a transfection efficiency of $27.0 \% \pm 2.7 \%$ and $11.7 \% \pm 2.1 \%$ using the same amount of pDNA and the same transfection method as for the PHH in HEK293 and HeLa cells, respectively. Using PPH-pDNA complexes, the percentage of GFP-expressing cells increased significantly with increasing N/P ratios (Fig. 4B+D). The highest N/P ratio of PMOXA- $b-\mathrm{PASP}(\mathrm{DET}) / \mathrm{pDNA}$ used in our study $(\mathrm{N} / \mathrm{P}=300)$ showed a GFP-transfection efficiency of $17.3 \% \pm 2.3 \%$ in HEK293 cells and $14.1 \%$ $\pm 2.4 \%$ in HeLa cells. Thus, our PPH resulted in a GFP expression level comparable to the one induced by bPEI (Fig. 4B+D). These results are comparable to findings from other recently developed polymer conjugates such as cyclodextrin-cored starlike carriers ${ }^{44}$ or PPH systems based on PLL ${ }^{45-47}$. However, it should be noted that a comparison of published results is difficult. Transfection efficiency depends on various factors such as cell line, pDNA promotor, or encoded protein. 


\section{Cytocompatibility of PMOXA-b-PASP(DET) as Gene Delivery System}

Transfection of cells with cationic reagents is often linked to cytotoxic effects since excessive positive charges destabilize the cell membrane. In general, high-molecular weight cationic polymers show higher cytotoxicity compared to low-molecular polycations ${ }^{48}$. This interaction is more likely when the polyplex dissociates in vivo and the free polycation interacts with cell membranes ${ }^{49}$. In vivo, accumulation of the compound in specific organs can lead to long-term side-effects. Therefore, we used the MTT assay to evaluate cytotoxicity of bPEI and PMOXA- $b$-PASP(DET) in presence (Fig. 5B+D) and more importantly in absence (Fig. 5A+C) of pDNA in two human cell lines.

bPEI resulted in strong cytotoxic effects (Fig. 5). A significant decrease in cell viability of more than $90 \%$ was detected for $163 \mu \mathrm{g} / \mathrm{mL}$ bPEI $(\mathrm{P}<0.001)$ in both cell lines $($ Fig. $5 \mathrm{~A}+\mathrm{C})$. This effect was even seen at low concentrations of $5 \mu \mathrm{g} / \mathrm{mL}$ bPEI with RCV of $0.58 \pm 0.10$ in HEK293 and $0.42 \pm 0.05$ in HeLa cells. Similar results were observed for bPEI-pDNA complexes (Fig. 5B+D). With increasing N/P ratios, the cell viability decreased significantly compared to control cells up to $96.3 \% \pm 2.4 \%$ in HEK293 and $93.1 \% \pm 4.3 \%$ in HeLa cells for N/P 300. Importantly, also N/P ratios used in transfection experiments (N/P 10 and N/P 20) resulted in significantly reduced cell viability.

In sharp contrast, our PPH resulted in high cell viability at all concentrations in absence and presence of pDNA (Fig. 5). In both cell lines no significant difference in cell viability compared to control cells was observed. There was no concentration-dependent effect, and even high concentrations or high N/P ratios were well tolerated (Fig. 5). Concentrations of $163 \mu \mathrm{g} / \mathrm{mL}$ 
(corresponding to an N/P ratio of 300 used for the transfection assay) resulted in excellent cell viability with a RCV of $0.89 \pm 0.07$ in HEK293 and $0.89 \pm 0.10$ in HeLa cells (Fig. 5A+C). Cells treated with PPH-pDNA nanoparticles showed superior cytocompatibility compared to bPEI at all N/P ratios (Fig. 5B+D).

Our findings are consistent with other PMOXA-based copolymer studies that also showed high cytocompatibility ${ }^{32}$. The PPH might benefit from the biocompatible features of the PMOXA block ${ }^{50}$. In addition, peptide-based polymer hybrids are biodegradable resulting in improved long-term cytocompatibility as also shown by other groups ${ }^{51}$.

The results of the MTT assay were confirmed by cell growth analysis (Fig. 6A). Transfection reagents are commonly used for pDNA delivery in vitro. However, they may interfere with cell replication and cell growth. Fischer et al. reported that polycations, such as bPEI, induce necrotic cell reactions ${ }^{16}$. Thus, we performed a CLSM study to analyze the effect of bPEI and our PPH on cell growth and morphology (Fig. 6A + Fig. S3). bPEI had a strong influence on the growth characteristics. Cells grew slowly and in clusters. This result was confirmed by analyzing the growth area of cells after $48 \mathrm{~h}$. bPEI decreased the growth of cells substantially, leading to a reduction of the overgrown area to only $2.0 \% \pm 0.9 \%$ at a concentration of $11 \mu \mathrm{g} / \mathrm{mL}$ compared to that of control cells (Fig. 6A). Furthermore, bPEI caused characteristic apoptotic features such as roundness, detachment, cytoplasmic blebbing, and debris (Fig. S3).

In sharp contrast, growth of cells cultured in medium containing our PPH was not impaired. Even at the highest concentrations of our $\mathrm{PPH}$, the relative growth area of $92.0 \% \pm 5.5 \%$ was not significantly different to that obtained for the control (Fig. 6A + Fig. S3). The highest concentration of $163 \mu \mathrm{g} / \mathrm{mL}$ corresponds to an N/P ratio of 300 . We conclude that our PPH (but 
not the commonly used transfection reagent bPEI) is not cytotoxic nor does it impair cell growth. These results are in line with the findings from the transfection experiments (Fig. 4). In addition, a pilot study in a vertebrate model, namely the zebrafish embryo model ${ }^{52-54}$, was performed to assess the safety of PPH in vivo. In accordance to OECD guidelines, zebrafish embryos were dechorionated before the incubation with test compounds due to the high molecular weight of the polymers. Zebrafish embryos incubated with our PPH showed a significantly increased survival rate as compared to bPEI ( $\mathrm{P}<0.001)$ : Concentrations of $27 \mu \mathrm{g} / \mathrm{mL}$ bPEI resulted in $100 \%$ mortality of zebrafish embryos after incubation for $24 \mathrm{~h}$. In sharp contrast, our PPH $(27 \mu \mathrm{g} / \mathrm{mL})$ was much better tolerated and the zebrafish embryos showed a survival rate of $48.9 \% \pm 3.8 \%$. These results are consistent with other recently published nanotoxicity studies using the zebrafish embryo assay ${ }^{55}$. Toxicity of bPEI was attributed to its cationic properties.

In summary, our PPH is characterized by a surprisingly high transfection efficiency despite a negative zeta potential and the protein-repellent properties of PMOXA ${ }^{56}$. Cell membranes have a negative surface charge predominantly because of the highly anionic glycosaminoglycans (GAGs). Therefore, interactions with the cell membrane are more pronounced if the nanocomplex has free positively charged groups leading to increased cell uptake. With this respect, the incubation conditions in cell culture do not precisely reflect the in vivo situation. In our experiments, cells are exposed during a long time (e.g. 48 hours) to high concentrations of nanoparticles. Under these conditions, a forced and unspecific uptake of nanoparticles may occur. In vivo, sophisticated targeting strategies will be needed to promote a comparable cellular uptake. On the other hand, highly cationic polymers, such as bPEI, may destabilize cellular membranes leading to toxic side effects. 
Thus, the better biocompatibility of our PPH may compensate for reduced transfection efficiency. A factor facilitating cell transfection using our $\mathrm{PPH}$ might be nanoparticle morphology. A small particle size (i.e. $100 \mathrm{~nm}$ ) and narrow size distribution favors pDNA delivery into cells ${ }^{57-59}$.

To further increase transfection efficiency using our PPH, the amino functionality of the $\mathrm{PPH}$ could be varied. This modification might improve the interaction with the cell membrane and/or enhance endosomal escape of internalized nanoparticles. A long-term perspective of our platform technology is the use for in vivo gene therapy. To this end, nanoparticles have to be modified with a targeting ligand to direct them to diseased tissues or organs in the body. Thus, a next generation of targeted nanoparticles will be needed to achieve this goal. The azide function of the PPH could be used for conjugation of targeting ligands via click chemistry. A possible in vivo application might be targeting of hepatocytes via the asialoglycoprotein receptor ${ }^{60,36}$. Therapeutic regimens for genetic diseases such as $\alpha 1$-antitrypsin deficiency ${ }^{61}$ as well as strategies against hepatocellular carcinoma ${ }^{62}$ might profit significantly from such a targeted gene therapy approach. 


\section{CONCLUSION}

The present paper describes the synthesis of a novel PPH system, namely PMOXA- $b$-PASP(DET), which efficiently complexed pDNA. The PPH formed nanocomplexes with different morphologies. At high N/P ratios, highly uniform PPH-pDNA nanoparticles $(\mathrm{d} 90 / 10=1.4)$ with a mean diameter around $100 \mathrm{~nm}$ were produced. The zeta potential of the resulting nanoparticles was slightly negative. Our PPH system showed excellent cytocompatibility. The pDNA transfection ability in HEK293 and HeLa cells was comparable to that of bPEI.

In conclusion, the combination of the biocompatible PMOXA backbone with the biodegradable PASP block is a novel and promising PPH system for efficient pDNA delivery without significant cytotoxic drawbacks. Additionally, our PPH system offers many possibilities for chemical modification. These interesting properties might be beneficial for in vivo applications, such as targeted gene delivery. 


\section{TABLES}

\section{Table 1: Characterization of PMOXA- $b$-PASP(DET).}

$\mathrm{DP}^{\mathrm{a}}$ : degree of polymerization index; $\mathrm{M}_{\mathrm{n}}$ : average molecular weight

\begin{tabular}{ccc}
\hline \multirow{2}{*}{ Sample } & \multicolumn{2}{c}{${ }^{1} \mathrm{HNMR}$} \\
\cline { 2 - 3 } & $\mathrm{DP}^{\mathrm{a}}$ & $M_{\mathrm{n}}$ \\
\hline $\mathrm{N}_{3}-\mathrm{PMOXA}_{\mathrm{n}}-\mathrm{NH}_{2}$ & 90 & 7700 \\
$\mathrm{~N}_{3}-\mathrm{PMOXA}_{\mathrm{n}}-\mathrm{PASP}(\mathrm{DET})_{\mathrm{m}}-\mathrm{NH}_{2}$ & $90: 50$ & 18100 \\
\hline
\end{tabular}




\section{FIGURE CAPTIONS}

Figure 1. Synthesis and Characterization of PMOXA-b-PASP(DET). (A) Schematic diagram illustrating the synthesis of PMOXA- $b$-PASP(DET). (1) Triflic anhydride, TEA, DCM, $-20^{\circ} \mathrm{C}$; (2) 2-methyl-2-oxazoline, acetonitrile, $80^{\circ} \mathrm{C}, \mathrm{NaN}_{3}$; (3) $\mathrm{NH}_{2}-\mathrm{NH}_{2} \cdot \mathrm{H}_{2} \mathrm{O}$, ethanol, r.t.; (4) B-benzyl L-aspartate anhydride, DMF, r.t. (5) DMF, DET, $40^{\circ} \mathrm{C}$. (B) ${ }^{1} \mathrm{H}-\mathrm{NMR}$ spectrum of $\mathrm{N}_{3}$-PMOXA$\mathrm{Ph}$ in $\mathrm{CDCl}_{3}$. (C) FT-IR spectrum of $\mathrm{N}_{3}-\mathrm{PMOXA-Ph}$. Stretching vibration of $\mathrm{C}=\mathrm{O}\left(1616 \mathrm{~cm}^{-1}\right)$.

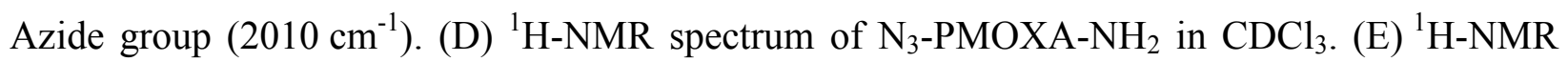
spectrum of $\mathrm{N}_{3}$-PMOXA- $b$-PBLA in CDCl3. (F) ${ }^{1} \mathrm{H}-\mathrm{NMR}$ spectrum of $\mathrm{N}_{3}$-PMOXA- $b$-PASP(DET) in $\mathrm{D}_{2} \mathrm{O}$.

Figure 2. Gel Retardation Assay. Migration of pDNA (4.7 kb), either native or complexed with increasing concentrations of PMOXA- $b$-PASP(DET). Different N/P ratios are shown. The samples were separated by electrophoresis on a $0.8 \%$ agarose gel in the presence of ethidium bromide. pDNA (lane 1) migrates as two bands, i.e. supercoiled and relaxed circular plasmid. An extended version of this figure showing that the complexation of pDNA with PMOXA- $b$-PASP(DET) is $\mathrm{pH}$ independent is given in the supporting information (Fig. S1).

\section{Figure 3. Characterization of Nanoparticles with Transmission Electron Microscopy (TEM) and Tunable Resistive Pulse Sensing (TRPS). Representative TEM images of PPH-pDNA complexes at N/P ratios of 20 (A), 50 (B), 100 (C), and 300 (D). Scale bars $=200 \mathrm{~nm}$. Additional images of PPH-pDNA nanoparticles at an N/P ratio of 300 are given}


in the supporting information (Fig. S2). Size analysis of PPH-pDNA nanoparticles at N/P ratios of $100(\mathrm{E})$ and $300(\mathrm{~F})$ using TRPS.

Figure 4. HEK293 and HeLa Cells Transfected with pDNA Encoding for Green Fluorescence Protein (GFP). Confocal laser scanning microscopy (CLSM) analysis of (A) HEK293 and (C) HeLa cells transfected with $1 \mu \mathrm{g}$ pDNA complexed with our polymerpeptide hybrid (PPH) system PMOXA- $b$-PASP(DET) or with bPEI. Representative images after transfection at different N/P ratios are shown. Scale bars $=200 \mu \mathrm{m}$. Percentages of GFP-positive (B) HEK293 and (D) HeLa cells of the same preparations were quantified using flow cytometry. Only N/P ratios, which did not show any cytotoxic effects in the CLSM analysis, were analyzed. Values are means \pm SD of four independent experiments per setting. Level of significance compared to pDNA control and corrected for multiple comparisons: $*=\mathrm{P}<0.001$.

Figure 5. Cell Viability Assay of HEK293 and HeLa Cells Determined by MTT Assay. (A) HEK293 and (C) HeLa cells were incubated with different amounts of our polymer-peptide hybrid (PPH) PMOXA-b-PASP(DET) or with bPEI for $24 \mathrm{~h}$. For better comparability with transfection experiments, the amounts of PPH needed to complex a hypothetical amount of $1 \mu \mathrm{g} / \mathrm{mL}$ pDNA were tested. Analysis of cell viability of (B) HEK293 and (D) HeLa cells incubated with polymer-pDNA nanocomplexes (PPH or bPEI) at different N/P ratios are shown. Values are means \pm SD of three independent experiments per setting. Level of significance compared to control (complexation medium only) and corrected for multiple comparisons: $*=\mathrm{P}<0.01, * *=\mathrm{P}<0.001$. 
Figure 6. Cell Growth Analysis. Cell growth analysis of GFP-expressing HEK293 cells 48 h after addition of our polymer-peptide hybrid (PPH) PMOXA- $b$-PASP(DET) or bPEI at different concentrations. Mean values of growth region of GFP-positive cells (\%) compared to control conditions (complexation medium only) are given $\pm \mathrm{SD}(\mathrm{n}=4)$. Level of significance compared to control and corrected for multiple comparisons: $*=\mathrm{P}<0.001$. Representative images are shown in the supporting information (Fig. S3). 


\section{Figures}

Figure 1.

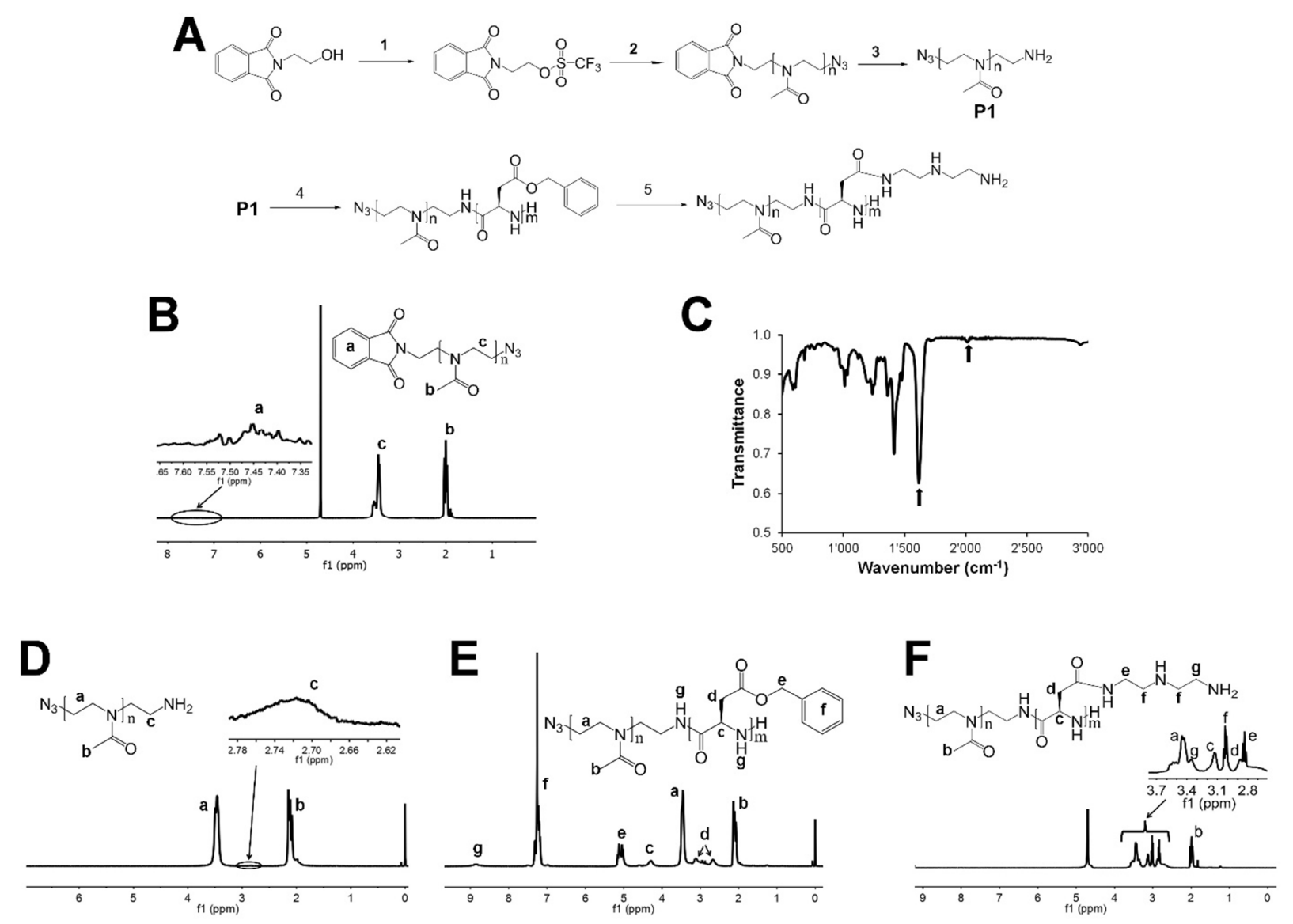

ACS Paragon Plus Environment 


\section{Figure 2.}

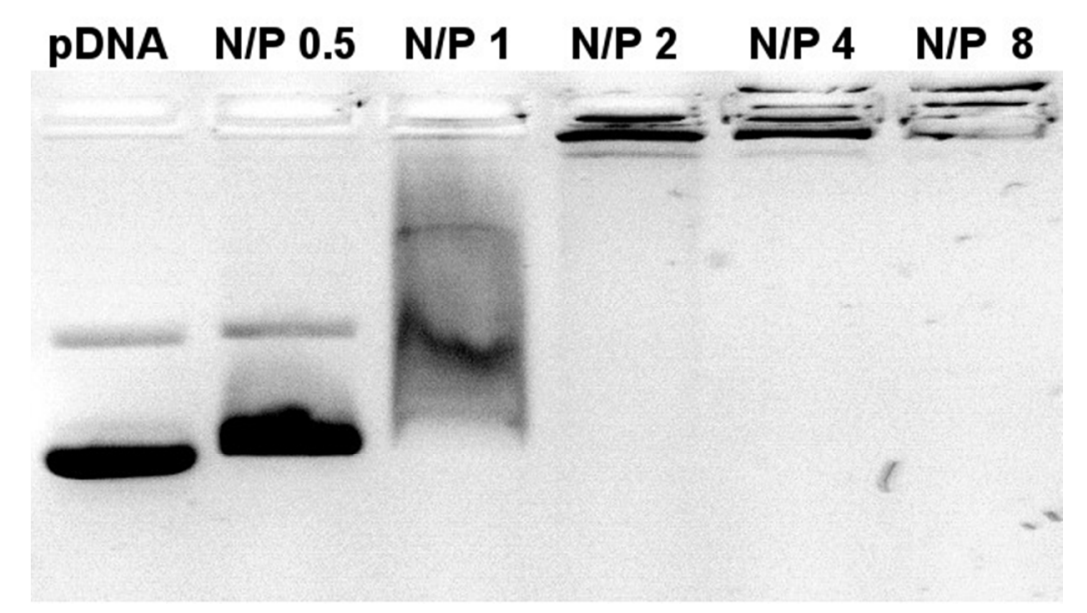

Figure 3.
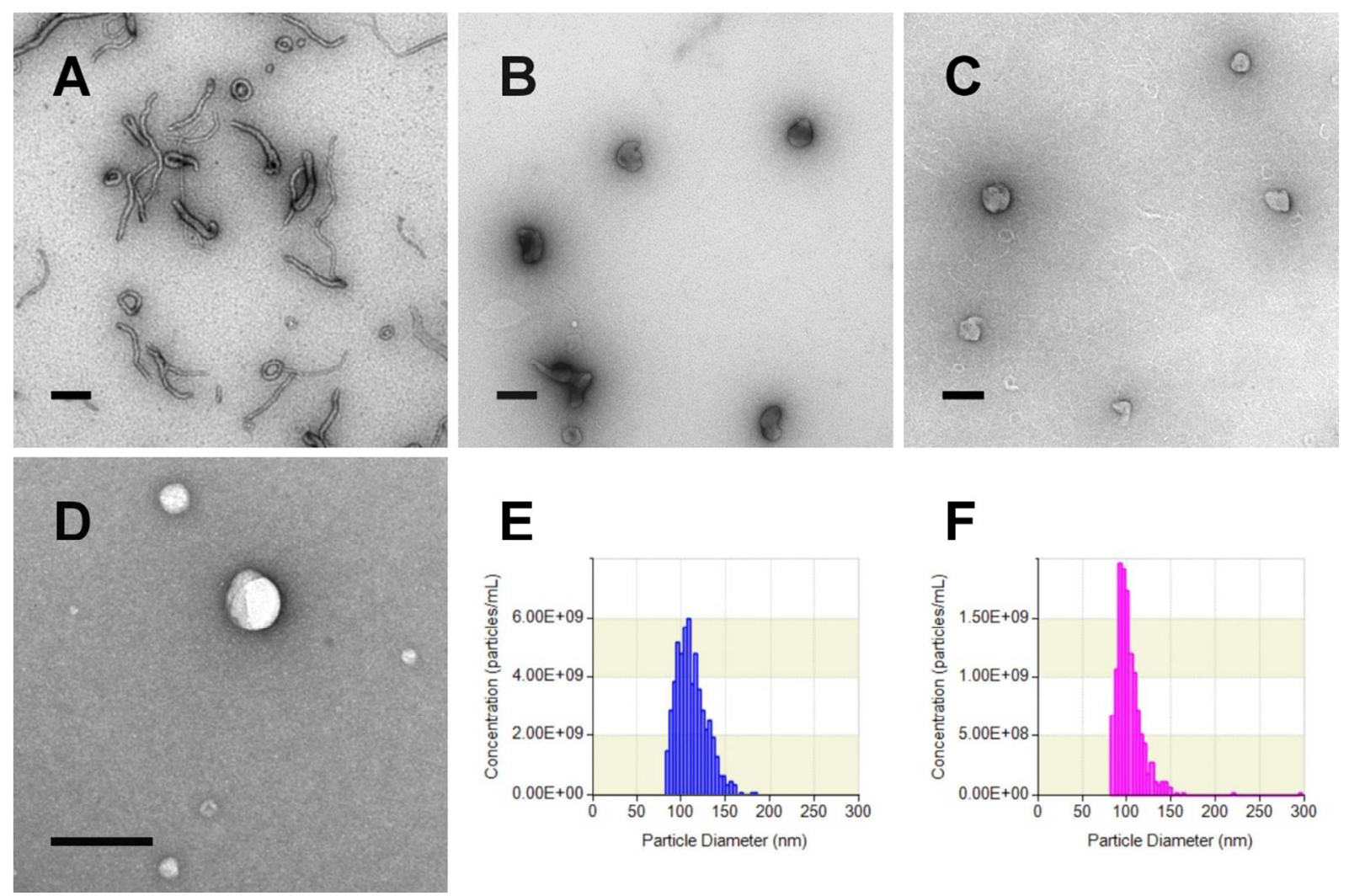
Figure 4.
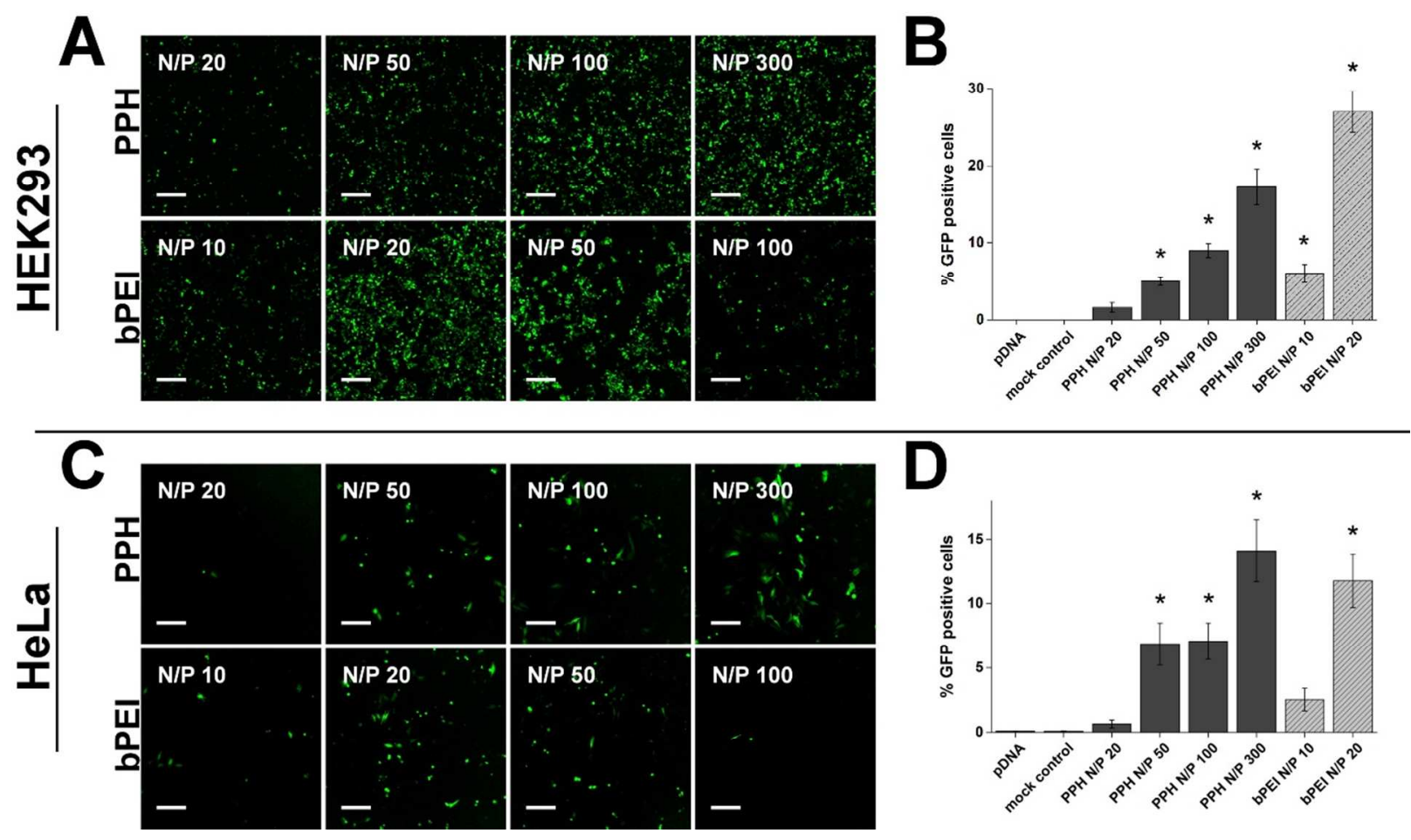
Figure 5.
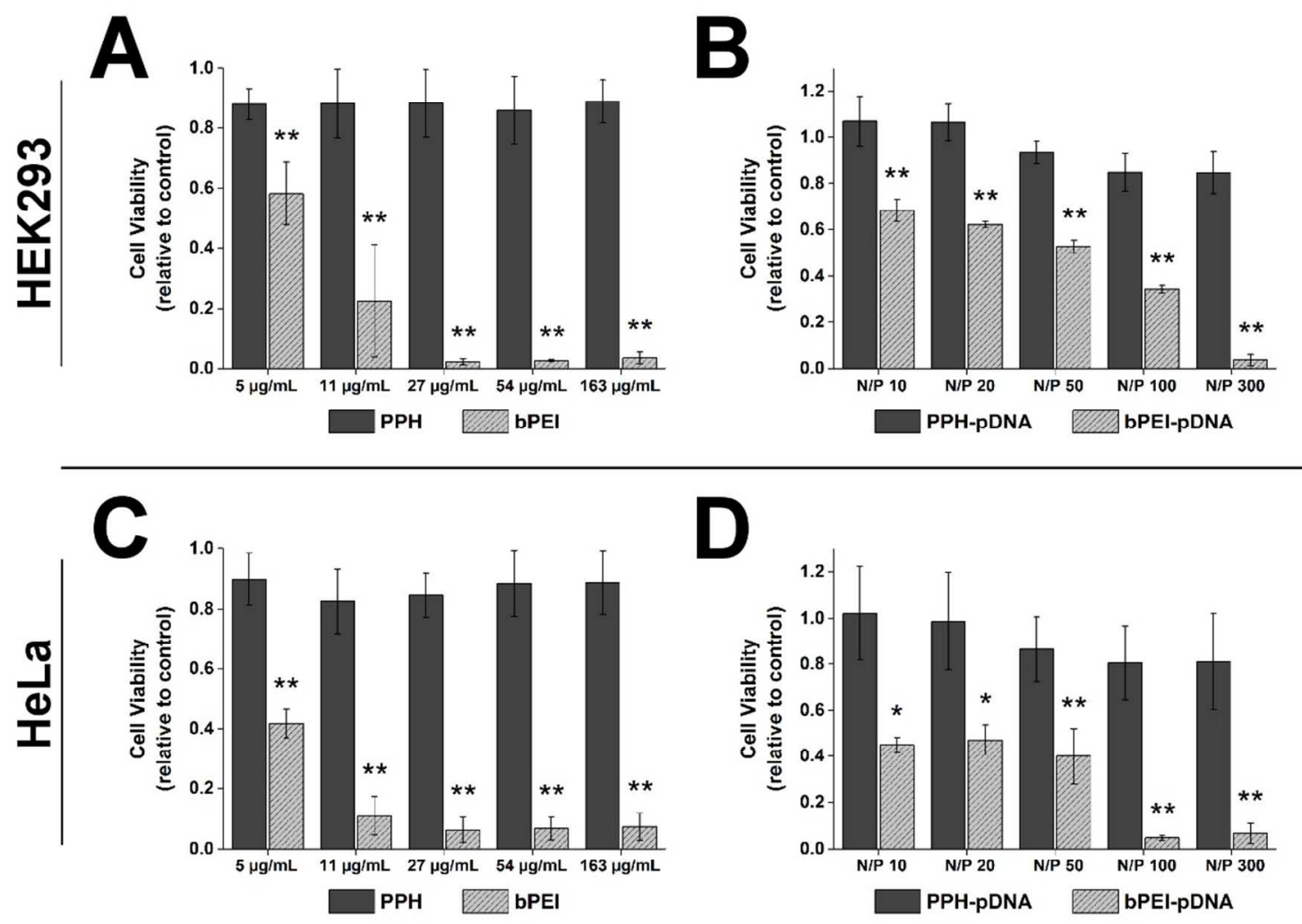

30

31

32

33

34

35

36

37

38

39

40

41

42

43

44

45

46

47

48

49

50

51

52

53

54

55

56

57

58

59

60 
Figure 6.

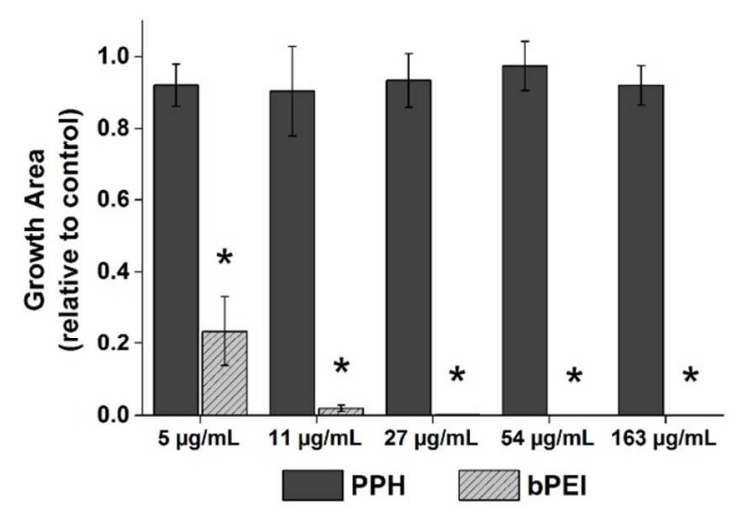

19

20

21

22

23

24

25

26

27

28

29

30

31

32

33

34

35

36

37

38

39

40

41

42

43

44

45

46

47

48

49

50

51

52

53

54

55

56

57

58

59

60

ACS Paragon Plus Environment 


\author{
AUTHOR INFORMATION \\ *Corresponding Author \\ Prof. Dr. Jörg Huwyler \\ Division of Pharmaceutical Technology \\ Department of Pharmaceutical Sciences \\ University of Basel \\ Klingelbergstrasse 50 \\ CH-4056 Basel \\ Switzerland \\ phone: +41 (0)61 2671513 \\ e-mail: joerg.huwyler@unibas.ch
}

\title{
Author Contributions
}

All authors contributed to the contents of this manuscript, and all of them gave their approval to the final version. $\$$ These authors contributed equally.

\section{ACKNOWLEDGMENT}

We acknowledge the financial support of the Swiss Centre of Applied Human Toxicology (SCAHT), Swiss National Science Foundation, and Swiss Nanoscience Institute (SNI). We thank the China Scholarship Council for supporting D. Wu. In addition, the authors thank Dr. Fabiola Porta and Stefan Siegrist for experimental support with the zebrafish embryo study, Prof. Markus Affolter for access to the zebrafish facility, Hubertus Kohler for support in the production of GFP expressing HEK 293 cells, and Izon Science (Oxford, UK) for assistance with TRPS measurements. Furthermore, we thank Dr. Silvia Rogers for editorial assistance. 


\title{
ASSOCIATED CONTENT
}

\section{Supporting Information}

Complexation of pDNA with PMOXA- $b$-PASP(DET) under different $\mathrm{pH}$ conditions (Figure S1), stability test of PPH-pDNA-nanoparticles using TEM analysis (Figure S2), and representative images of GFP expressing HEK293 cells $48 \mathrm{~h}$ after addition of PMOXA- $b$-PASP(DET) or bPEI at different concentrations (Figure S3) are given in the Supporting Information. This material is available free of charge via the Internet at http://pubs.acs.org/.

\begin{abstract}
ABBREVIATIONS
bPEI, branched poly(ethylenimine); CLSM, confocal laser scanning microscopy; DCM, dichloromethane; DMEM, Dulbecco's modified Eagle's culture medium; DET, diethylenetriamine; FCS, fetal calf serum; FT-IR, Fourier transform infrared spectroscopy; GFP, green fluorescence protein; HEK293 cells, human embryonic kidney cells; N/P, nitrogen to phosphate; PASP, poly(aspartic acid); pDNA, plasmid DNA; PEG, polyethylene glycol; PMOXA, poly(2-methyl-2-oxazoline); PPH, polymer-peptide-hybrid; RT, room temperature; TBE, tris/borate/EDTA buffer; TBS, tris-buffered saline; TEA, trimethylamine; TEM, transmission electron microscopy; TRPS, tunable resistive pulse sensing;
\end{abstract}




\section{REFERENCES}

(1) Gene Therapy Clinical Trials Worldwide Home Page. http://www.abedia.com/wiley/phases.php (accessed Oct 3, 2014).

(2) Wicki, A.; Witzigmann, D.; Balasubramanian, V.; Huwyler, J. Nanomedicine in Cancer Therapy: Challenges, Opportunities, and Clinical Applications. J. Controlled Release 2015, 200, 138-157.

(3) Dey, D.; Inayathullah, M.; Lee, A. S.; LeMieux, M. C.; Zhang, X.; Wu, Y.; Nag, D.; De Almeida, P. E.; Han, L.; Rajadas, J. Efficient Gene Delivery of Primary Human Cells Using Peptide Linked Polyethylenimine Polymer Hybrid. Biomaterials 2011, 32, 46474658.

(4) Pack, D. W.; Hoffman, A. S.; Pun, S.; Stayton, P. S. Design and Development of Polymers for Gene Delivery. Nat. Rev. Drug Discovery 2005, 4, 581-593.

(5) Palivan, C. G.; Fischer-Onaca, O.; Delcea, M.; Itel, F.; Meier, W. Protein-Polymer Nanoreactors for Medical Applications. Chem. Soc. Rev. 2012, 41, 2800-2823.

(6) Kataoka, K.; Harada, A.; Nagasaki, Y. Block Copolymer Micelles for Drug Delivery: Design, Characterization and Biological Significance. Adv. Drug Delivery Rev. 2012, 64, $37-48$.

(7) Mei, Y.; Beers, K. L.; Byrd, H. C. M.; VanderHart, D. L.; Washburn, N. R. Solid-Phase ATRP Synthesis of Peptide-Polymer Hybrids. J. Am. Chem. Soc. 2004, 126, 3472-3476.

(8) Zhong, Z.; Song, Y.; Engbersen, J. F. J.; Lok, M. C.; Hennink, W. E.; Feijen, J. A Versatile Family of Degradable Non-Viral Gene Carriers Based on Hyperbranched Poly(ester Amine)s. J. Controlled Release 2005, 109, 317-329. 
(9) Kim, T.; Ou, M.; Lee, M.; Kim, S. W. Arginine-Grafted Bioreducible Poly(disulfide Amine) for Gene Delivery Systems. Biomaterials 2009, 30, 658-664.

(10) Klok, H.-A. Peptide/Protein-Synthetic Polymer Conjugates: Quo Vadis. Macromolecules 2009, 42, 7990-8000.

(11) Zhang, S.; Zhao, Y.; Zhao, B.; Wang, B. Hybrids of Nonviral Vectors for Gene Delivery. Bioconjugate Chem. 2010, 21, 1003-1009.

(12) Mahato, M.; Kumar, P.; Sharma, A. K. Amphiphilic Polyethylenimine Polymers Mediate Efficient Delivery of DNA and siRNA in Mammalian Cells. Mol. Biosyst. 2013, 9, 780791.

(13) Zhang, Q.-F.; Yu, Q.-Y.; Geng, Y.; Zhang, J.; Wu, W.-X.; Wang, G.; Gu, Z.; Yu, X.-Q. Ring-Opening Polymerization for Hyperbranched Polycationic Gene Delivery Vectors with Excellent Serum Tolerance. ACS Appl. Mater. Interfaces 2014, 6, 15733-15742.

(14) Kim, H. J.; Miyata, K.; Nomoto, T.; Zheng, M.; Kim, A.; Liu, X.; Cabral, H.; Christie, R. J.; Nishiyama, N.; Kataoka, K. siRNA Delivery from Triblock Copolymer Micelles with Spatially-Ordered Compartments of PEG Shell, siRNA-Loaded Intermediate Layer, and Hydrophobic Core. Biomaterials 2014, 35, 4548-4556.

(15) Winter, J.; Link, S.; Witzigmann, D.; Hildenbrand, C.; Previti, C.; Diederichs, S. LoopmiRs: Active microRNAs Generated from Single-Stranded Loop Regions. Nucleic Acids Res. 2013, 41, 5503-5512.

(16) Fischer, D.; Li, Y.; Ahlemeyer, B.; Krieglstein, J.; Kissel, T. In Vitro Cytotoxicity Testing of Polycations: Influence of Polymer Structure on Cell Viability and Hemolysis. Biomaterials 2003, 24, 1121-1131. 
(17) Wong, S. Y.; Pelet, J. M.; Putnam, D. Polymer Systems for Gene Delivery-Past, Present, and Future. Prog. Polym. Sci. 2007, 32, 799-837.

(18) Zhu, Y.; Tang, G.-P.; Xu, F.-J. Efficient poly(N-3-Hydroxypropyl)aspartamide-Based Carriers via ATRP for Gene Delivery. ACS Appl. Mater. Interfaces 2013, 5, 1840-1848.

(19) Zhou, D.; Li, C.; Hu, Y.; Zhou, H.; Chen, J.; Zhang, Z.; Guo, T. PLL/pDNA/P(His-CoDMAEL) Ternary Complexes: Assembly, Stability and Gene Delivery. J. Mater. Chem. 2012, 22, 10743-10751.

(20) Zhou, D.; Li, C.; Hu, Y.; Zhou, H.; Chen, J.; Zhang, Z.; Guo, T. The Effects of a Multifunctional Oligomer and Its Incorporation Strategies on the Gene Delivery Efficiency of poly(L-Lysine). Chem. Commun. (Cambridge, U.K.) 2012, 48, 4594-4596.

(21) Newland, B.; Zheng, Y.; Jin, Y.; Abu-Rub, M.; Cao, H.; Wang, W.; Pandit, A. Single Cyclized Molecule versus Single Branched Molecule: A Simple and Efficient 3D "Knot" Polymer Structure for Nonviral Gene Delivery. J. Am. Chem. Soc. 2012, 134, 4782-4789.

(22) Zhao, T.; Zhang, H.; Newland, B.; Aied, A.; Zhou, D.; Wang, W. Significance of Branching for Transfection: Synthesis of Highly Branched Degradable Functional Poly(dimethylaminoethyl Methacrylate) by Vinyl Oligomer Combination. Angew. Chem. 2014, 126, 6209-6214.

(23) Hentschel, J.; Bleek, K.; Ernst, O.; Lutz, J.-F.; Boerner, H. G. Easy Access to Bioactive Peptide-Polymer Conjugates via RAFT. Macromolecules 2008, 41, 1073-1075.

(24) Hoogenboom, R. Poly(2-Oxazoline)s: A Polymer Class with Numerous Potential Applications. Angew. Chem. Int. Ed. Engl. 2009, 48, 7978-7994.

(25) Konradi, R.; Pidhatika, B.; Mühlebach, A.; Textor, M. Poly-2-Methyl-2-Oxazoline: A Peptide-like Polymer for Protein-Repellent Surfaces. Langmuir 2008, 24, 613-616. 
(26) Viegas, T. X.; Bentley, M. D.; Harris, J. M.; Fang, Z.; Yoon, K.; Dizman, B.; Weimer, R.; Mero, A.; Pasut, G.; Veronese, F. M. Polyoxazoline: Chemistry, Properties, and Applications in Drug Delivery. Bioconjugate Chem. 2011, 22, 976-986.

(27) Fishburn, C. S. The Pharmacology of PEGylation: Balancing PD with PK to Generate Novel Therapeutics. J. Pharm. Sci. 2008, 97, 4167-4183.

(28) Pidhatika, B.; Rodenstein, M.; Chen, Y.; Rakhmatullina, E.; Mühlebach, A.; Acikgöz, C.; Textor, M.; Konradi, R. Comparative Stability Studies of poly(2-Methyl-2-Oxazoline) and Poly(ethylene Glycol) Brush Coatings. Biointerphases 2012, 7, 1.

(29) Canalle, L. A.; Löwik, D. W. P. M.; van Hest, J. C. M. Polypeptide-Polymer Bioconjugates. Chem. Soc. Rev. 2010, 39, 329-353.

(30) Morell, M.; Puiggalí, J. Hybrid Block Copolymers Constituted by Peptides and Synthetic Polymers: An Overview of Synthetic Approaches, Supramolecular Behavior and Potential Applications. Polymers 2013, 5, 188-224.

(31) Osada, K.; Kataoka, K. Drug and Gene Delivery Based on Supramolecular Assembly of PEG-Polypeptide Hybrid Block Copolymers. In Peptide Hybrid Polymers; Klok, H. A.; Schlaad, H., Eds.; Springer-Verlag Berlin: Berlin, 2006; Vol. 202, pp. 113-153.

(32) Camblin, M.; Detampel, P.; Kettiger, H.; Wu, D.; Balasubramanian, V.; Huwyler, J. Polymersomes Containing Quantum Dots for Cellular Imaging. Int. J. Nanomed. 2014, 9 , $2287-2298$.

(33) Smicius, R.; Engels, J. W. Preparation of Zwitterionic Ribonucleoside Phosphoramidites for Solid-Phase siRNA Synthesis. J. Org. Chem. 2008, 73, 4994-5002. 
(34) Vinson, N.; Gou, Y.; Becer, C. R.; Haddleton, D. M.; Gibson, M. I. Optimised “click" Synthesis of Glycopolymers with Mono/di- and Trisaccharides. Polym. Chem. 2010, 2, $107-113$.

(35) Osby, J. O.; Martin, M. G.; Ganem, B. An Exceptionally Mild Deprotection of Phthalimides. Tetrahedron Lett. 1984, 25, 2093-2096.

(36) Kettiger, H.; Schipanski, A.; Wick, P.; Huwyler, J. Engineered Nanomaterial Uptake and Tissue Distribution: From Cell to Organism. Int. J. Nanomed. 2013, 8, 3255-3269.

(37) Hu, Y.; Zhu, Y.; Yang, W. T.; Xu, F. J. New Star-Shaped Carriers Composed of BCyclodextrin Cores and Disulfide-Linked Poly(glycidyl Methacrylate) Derivative Arms with Plentiful Flanking Secondary Amine and Hydroxyl Groups for Highly Efficient Gene Delivery. ACS Appl. Mater. Interfaces 2013, 5, 703-712.

(38) Miyata, K.; Oba, M.; Nakanishi, M.; Fukushima, S.; Yamasaki, Y.; Koyama, H.; Nishiyama, N.; Kataoka, K. Polyplexes from Poly(aspartamide) Bearing 1,2Diaminoethane Side Chains Induce pH-Selective, Endosomal Membrane Destabilization with Amplified Transfection and Negligible Cytotoxicity. J. Am. Chem. Soc. 2008, 130, $16287-16294$.

(39) Xu, A.; Yao, M.; Xu, G.; Ying, J.; Ma, W.; Li, B.; Jin, Y. A Physical Model for the SizeDependent Cellular Uptake of Nanoparticles Modified with Cationic Surfactants. Int. J. Nanomed. 2012, 7, 3547-3554.

(40) Jiang, S.; Eltoukhy, A. A.; Love, K. T.; Langer, R.; Anderson, D. G. Lipidoid-Coated Iron Oxide Nanoparticles for Efficient DNA and siRNA Delivery. Nano Lett. 2013, 13, 10591064. 
(41) Karmali, P. P.; Simberg, D. Interactions of Nanoparticles with Plasma Proteins: Implication on Clearance and Toxicity of Drug Delivery Systems. Expert Opin. Drug Delivery 2011, 8, 343-357.

(42) Ishiwata, H.; Suzuki, N.; Ando, S.; Kikuchi, H.; Kitagawa, T. Characteristics and Biodistribution of Cationic Liposomes and Their DNA Complexes. J. Controlled Release 2000, 69, 139-148.

(43) Iwai, R.; Haruki, R.; Nemoto, Y.; Nakayama, Y. Enhanced Transfection Efficiency of poly(N,N-Dimethylaminoethyl Methacrylate)-Based Deposition Transfection by Combination with Tris(hydroxymethyl)aminomethane. Bioconjugate Chem. 2013, 24, $159-166$.

(44) Li, R. Q.; Niu, Y. L.; Zhao, N. N.; Yu, B. R.; Mao, C.; Xu, F. J. Series of New BCyclodextrin-Cored Starlike Carriers for Gene Delivery. ACS Appl. Mater. Interfaces 2014, 6, 3969-3978.

(45) Von Erlach, T.; Zwicker, S.; Pidhatika, B.; Konradi, R.; Textor, M.; Hall, H.; Lühmann, T. Formation and Characterization of DNA-Polymer-Condensates Based on poly(2-Methyl2-Oxazoline) Grafted poly(L-Lysine) for Non-Viral Delivery of Therapeutic DNA. Biomaterials 2011, 32, 5291-5303.

(46) Fukushima, S.; Miyata, K.; Nishiyama, N.; Kanayama, N.; Yamasaki, Y.; Kataoka, K. PEGylated Polyplex Micelles from Triblock Catiomers with Spatially Ordered Layering of Condensed pDNA and Buffering Units for Enhanced Intracellular Gene Delivery. J. Am. Chem. Soc. 2005, 127, 2810-2811.

Cai, X.; Dong, C.; Dong, H.; Wang, G.; Pauletti, G. M.; Pan, X.; Wen, H.; Mehl, I.; Li, Y.; Shi, D. Effective Gene Delivery Using Stimulus-Responsive Catiomer Designed with 
Redox-Sensitive Disulfide and Acid-Labile Imine Linkers. Biomacromolecules 2012, 13, 1024-1034.

(48) Car, A.; Baumann, P.; Duskey, J. T.; Chami, M.; Bruns, N.; Meier, W. pH-Responsive PDMS-B-PDMAEMA Micelles for Intracellular Anticancer Drug Delivery. Biomacromolecules 2014, 15, 3235-3245.

(49) Kircheis, R.; Wightman, L.; Wagner, E. Design and Gene Delivery Activity of Modified Polyethylenimines. Adv. Drug Delivery Rev. 2001, 53, 341-358.

(50) Isaacman, M. J.; Corigliano, E. M.; Theogarajan, L. S. Stealth Polymeric Vesicles via Metal-Free Click Coupling. Biomacromolecules 2013, 14, 2996-3000.

(51) Lynn, D. M.; Langer, R. Degradable Poly( $\beta$-Amino Esters): Synthesis, Characterization, and Self-Assembly with Plasmid DNA. J. Am. Chem. Soc. 2000, 122, 10761-10768.

(52) Fako, V. E.; Furgeson, D. Y. Zebrafish as a Correlative and Predictive Model for Assessing Biomaterial Nanotoxicity. Adv. Drug Delivery Rev. 2009, 61, 478-486.

(53) Hu, Y.-L.; Qi, W.; Han, F.; Shao, J.-Z.; Gao, J.-Q. Toxicity Evaluation of Biodegradable Chitosan Nanoparticles Using a Zebrafish Embryo Model. Int. J. Nanomed. 2011, 6, $3351-3359$.

(54) Duan, J.; Yu, Y.; Li, Y.; Yu, Y.; Sun, Z. Cardiovascular Toxicity Evaluation of Silica Nanoparticles in Endothelial Cells and Zebrafish Model. Biomaterials 2013, 34, 58535862.

(55) Rizzo, L. Y.; Golombek, S. K.; Mertens, M. E.; Pan, Y.; Laaf, D.; Broda, J.; Jayapaul, J.; Möckel, D.; Subr, V.; Hennink, W. E.; Storm, G.; Simon, U.; Jahnen-Dechent, W.; Kiessling, F.; Lammers, T. In Vivo Nanotoxicity Testing Using the Zebrafish Embryo Assay. J. Mater. Chem. B 2013, 1, 3918-3925. 
(56) Byeon, J. H.; Kim, H.-K.; Thompson, D. H.; Roberts, J. T. Aerosol-Based Fabrication of Modified Chitosans and Their Application for Gene Transfection. ACS Appl. Mater. Interfaces 2014, 6, 4597-4602.

(57) Van de Wetering, P.; Moret, E. E.; Schuurmans-Nieuwenbroek, N. M. E.; van Steenbergen, M. J.; Hennink, W. E. Structure-Activity Relationships of Water-Soluble Cationic Methacrylate/Methacrylamide Polymers for Nonviral Gene Delivery. Bioconjugate Chem. 1999, 10, 589-597.

(58) Zhang, S.; Li, J.; Lykotrafitis, G.; Bao, G.; Suresh, S. Size-Dependent Endocytosis of Nanoparticles. Adv. Mater. Weinheim 2009, 21, 419-424.

(59) Lu, F.; Wu, S.-H.; Hung, Y.; Mou, C.-Y. Size Effect on Cell Uptake in Well-Suspended, Uniform Mesoporous Silica Nanoparticles. Small 2009, 5, 1408-1413.

(60) Detampel, P.; Witzigmann, D.; Krähenbühl, S.; Huwyler, J. Hepatocyte Targeting Using Pegylated Asialofetuin-Conjugated Liposomes. J. Drug Targeting 2013, 22, 232-241.

(61) Stoller, J. K.; Aboussouan, L. S. Alpha1-Antitrypsin Deficiency. Lancet 2005, 365, 22252236.

(62) Peng, D.-J.; Sun, J.; Wang, Y.-Z.; Tian, J.; Zhang, Y.-H.; Noteborn, M. H. M.; Qu, S. Inhibition of Hepatocarcinoma by Systemic Delivery of Apoptin Gene via the Hepatic Asialoglycoprotein Receptor. Cancer Gene Ther. 2007, 14, 66-73. 


\section{TABLE OF CONTENTS GRAPHIC}

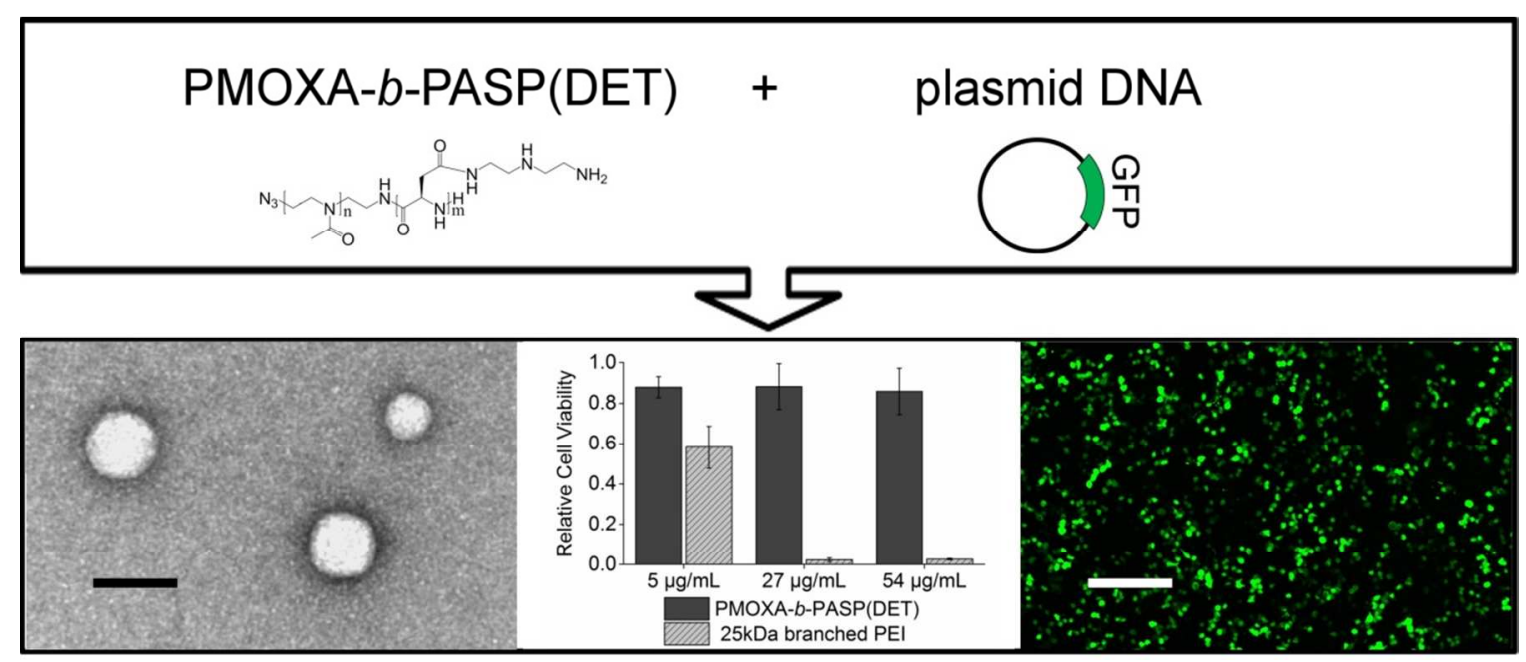

